Article

\title{
Relationships between Occupational Stress, Change in Work Environment during the COVID-19 Pandemic, and Depressive and Anxiety Symptoms among Non-Healthcare Workers in Japan: A Cross-Sectional Study
}

\author{
Yasuhiko Deguchi *, Shinichi Iwasaki, Akihiro Niki, Aya Kadowaki, Tomoyuki Hirota, Yoshiki Shirahama, \\ Yoko Nakamichi, Yutaro Okawa, Yuki Uesaka and Koki Inoue
}

\section{check for}

updates

Citation: Deguchi, Y.; Iwasaki, S.;

Niki, A.; Kadowaki, A.; Hirota, T.;

Shirahama, Y.; Nakamichi, Y.; Okawa,

Y.; Uesaka, Y.; Inoue, K. Relationships between Occupational Stress, Change in Work Environment during the COVID-19 Pandemic, and Depressive and Anxiety Symptoms among Non-Healthcare Workers in Japan: A Cross-Sectional Study. Int. J. Environ. Res. Public Health 2022, 19, 983.

https://doi.org/10.3390/ ijerph19020983

Academic Editors: Andrea Fiorillo, Maurizio Pompili and Gaia Sampogna

Received: 6 December 2021

Accepted: 13 January 2022

Published: 16 January 2022

Publisher's Note: MDPI stays neutral with regard to jurisdictional claims in published maps and institutional affiliations.

Copyright: (C) 2022 by the authors. Licensee MDPI, Basel, Switzerland. This article is an open access article distributed under the terms and conditions of the Creative Commons Attribution (CC BY) license (https:// creativecommons.org/licenses/by/ $4.0 /)$.

\begin{abstract}
Department of Neuropsychiatry, Graduate School of Medicine, Osaka City University, Osaka 545-8585, Japan siwasaki@med.osaka-cu.ac.jp (S.I.); aki29seiya@yahoo.co.jp (A.N.); ak.peridot@gmail.com (A.K.); tomo19890323@gmail.com (T.H.); skybluegreen.2112@gmail.com (Y.S.); yoko.nakamichi.4@gmail.com (Y.N.); koro3koro3jp@gmail.com (Y.O.); uesakayuki@yahoo.co.jp (Y.U.); kokii@med.osaka-cu.ac.jp (K.I.)

* Correspondence: m2012567@med.osaka-cu.ac.jp
\end{abstract}

\begin{abstract}
This study aims to clarify the effect of occupational stress and changes in the work environment on non-healthcare workers' (HCWs) mental health during the third wave of the COVID-19 pandemic in Japan. A web-based, cross-sectional survey was conducted from 16 to 17 December 2020. Data from 807 non-HCWs were included. We evaluated occupational stress using the Generic Job Stress Questionnaire (GJSQ). Depressive and anxiety symptoms were assessed using the Japanese version of the Patient Health Questionnaire-9 and the Generalized Anxiety Disorder 7-item scale, respectively. We collected demographic variables, work-related variables, and the variables associated with COVID-19. The adjusted odds ratios for depressive and anxiety groups were estimated using multivariate logistic regression analyses, adjusted for all the demographic variables, work-related variables, COVID-19-related variables, and the six subdivided GJSQ subscales. The results confirm a relationship between variance in workload, job future ambiguity, social support from coworkers, having contact with COVID-19 patients, and depressive and anxiety symptoms. Paying attention to job future ambiguity, the variance in workload at the workplace and individual perspectives, promoting contact and support among coworkers using online communication tools, and reducing contact with COVID-19 patients, will be useful for decreasing the depressive and anxiety symptoms among non-HCWs.
\end{abstract}

Keywords: COVID-19; occupational stress; mental health; non-healthcare workers; job future ambiguity; variance in workload; depressive symptoms; anxiety symptoms

\section{Introduction}

Since 2020, the coronavirus disease 2019 (COVID-19) pandemic has been the main concern worldwide. As of 14 November 2021, over 252 million confirmed cases and more than 5 million deaths were reported by the World Health Organization [1]. In Japan, states of emergency were declared four times-March to May 2020, January to March, April to June, and July to September 2021 - and efforts to maintain physical distancing and self-isolation were enforced. The prolonged COVID-19 pandemic also had a significant impact on global mental health.

The pandemic and the related containment measures (quarantine, physical distancing, and self-isolation) can have a detrimental impact on mental health. Concerns about one's health and that of their loved ones, as well as the uncertainty about the future, can generate or exacerbate fear, depression, and anxiety, and these concerns, if prolonged, can increase the risk of serious and disabling mental health conditions among adult males and females [2]. A longitudinal study in the UK demonstrated prolonged deterioration 
in mental health for all age groups and genders, not only immediately after the initial lockdown, but also in the subsequent months when restrictions were eased [3]. Fiorillo and Gorwood stated that the pandemic will be over, but its effects on the mental health and well-being of the general population, health professionals, and vulnerable people will remain for a long time [2]. Therefore, further research that aims to evaluate the impact of the pandemic on mental health is needed.

Among the general global population, relatively high rates of depressive symptoms, from $14.6 \%$ to $48.3 \%$ [4-6], and anxiety symptoms, from $6.33 \%$ to $50.9 \%$ [4-6], have been reported during the COVID-19 pandemic in three systematic reviews and a multinational meta-analysis. In addition, these studies identified several risk factors associated with depressive and anxiety symptoms [4-6]: being female, in a younger age group, a student, having a lower socioeconomic status (e.g., living in rural areas, having an unstable income, and having lower education), and being unemployed; experiencing loneliness; being divorced, widowed, or single; not having a child; worrying about being infected; being at a high risk of contracting COVID-19; and frequent exposure to social media or news about COVID-19.

The COVID-19 pandemic overwhelmed hospitals worldwide, and healthcare workers (HCWs) have faced risks of poor mental health conditions. Systematic reviews and metaanalyses have consistently demonstrated an increased incidence of poor mental health, including elevated depressive and anxiety symptoms, psychological burden, and stress reaction, among HCWs during the COVID-19 pandemic [5,7-15]. In addition, previous research found differences in the mental health conditions between HCWs and non-HCWs in the early phase of the COVID-19 pandemic [16-18]. For example, two studies in China reported that HCWs and non-HCWs experienced similar levels of anxiety and depression [16], and the prevalence of depression and anxiety was greater among HCWs than non-HCWs [17]. Another study conducted during the first wave of the COVID-19 pandemic in Japan demonstrated that psychological distress, including fatigue, anxiety, and depression, increased significantly more among HCWs than non-HCWs [18].

However, the global COVID-19 pandemic has continued for more than a year, and its psychological effects on non-HCWs may have further increased. In fact, the work environment dramatically changed during the pandemic. For instance, the prevention of infection, using methods that include avoiding situations with the "three Cs" (i.e., enclosed space, crowding, and closed contact), physical distancing among coworkers or clients, and remote working, became a requirement. Further, the anxiety and fear regarding workplace infection, future income or workplace prospects, and unemployment continue to affect nonHCWs. A study including 123,768 factory workers in China, reported that the prevalence of depressive and anxiety symptoms was $22.8 \%$ and $3.4 \%$, and having COVID-19 confirmed cases in the community, having COVID-19 confirmed friends, a poor health status, and alcoholism were associated with an increased risk of depressive/anxiety symptoms [19]. However, few studies examined the psychological effect of the COVID-19 pandemic on non-HCWs.

Before the COVID-19 pandemic, longitudinal studies and meta-analyses demonstrated that having a higher quantitative workload, lower job control, lower social support, and higher job strain was associated with an elevated risk of depressive symptoms [20-23]. Workers exposed to high psychological demands and low job control have a higher tendency to take sickness absence due to a mental disorder than workers with no exposure to such demands [24]. Some studies on occupational stress among HCWs have been conducted during the COVID-19 pandemic. A study including neurologists in Norway, reported that changed work routines and access to resources and the perception that medical follow-ups were unsatisfactory were associated with a high degree of burden and stress; however, the fear of becoming infected and ill was not an important contributor [25]. Another study with frontline nurses in China reported that the number of daily working hours, service years, and weekly night shifts, and the level of academic qualification were major factors related to job stress [26]. 
However, little is known about (a) what occupational stress factors impact non- HCWs' mental health during the COVID-19 pandemic and (b) what work environment factor changes due to COVID-19 impact non-HCWs' mental health. Therefore, we hypothesized that occupational stress during the COVID-19 pandemic and work environment changes due to the pandemic would significantly impact non-HCWs' mental health. This study aims to clarify the effect of occupational stress and change in the work environment on non-HCWs' mental health during the third wave of the COVID-19 pandemic in Japan.

\section{Materials and Methods}

\subsection{Study Design, Participants, and Procedure}

A web-based, cross-sectional survey was conducted in Japan through an online research company, Macromill, Inc. Japan, from 16 to 17 December 2020, which was during the third wave of the COVID-19 pandemic. The study used the following inclusion criteria for participants: (a) living in Japan, (b) being employed, and (c) being between 20 and 65 years of age. Previous studies using the Patient Health Questionnaire-9 (PHQ-9) and the Generalized Anxiety Disorder 7-item scale (GAD-7) reported prevalence rates of depressive and anxiety symptoms in the general population to be about 30-40\% [27-29]. We aimed to recruit about 1000 Japanese workers with different employment statuses from a pool of approximately 10 million individuals registered with Macromill, Inc. A total of 1070 workers participated. We excluded participants with at least one missing entry on the questionnaire and 58 individuals who described themselves as HCWs in order to have a sample of only non-HCWs. Thus, non-HCWs consisted of all kinds of workers except HCWs, and the final analytic sample included a total of 807 eligible participants.

\subsection{Measures of Occupational Stress}

We evaluated occupational stress using the Generic Job Stress Questionnaire (GJSQ) developed by the National Institute for Occupational Safety and Health (NIOSH) [30]. The Japanese version of the GJSQ demonstrated sufficient reliability and validity [31,32]. The NIOSH permits that the GJSQ subscales be used independently to evaluate occupational stress [30]. Based on the NIOSH job stress model [30], we focused on four subscales (quantitative workload, job control, variance in workload, and job future ambiguity) to evaluate occupational stress. Two subscales were used to evaluate social support (from supervisors and coworkers), which functions as a buffering factor, according to the results of many previous studies on the relationship between psychiatric symptoms and occupational stress [20-23,33-37]. Items on the GJSQ are positively oriented and higher scores indicate lower stress levels for the job control and social support items. In contrast, the other items are negatively oriented and higher scores indicate greater stress levels.

\subsection{Measures of Depressive and Anxiety Symptoms}

We evaluated depressive symptoms using the Japanese version of the PHQ-9, which has been validated $[38,39]$. The scale includes nine items regarding the frequency of problems bothering participants in the past two weeks, and each item is rated from 0 (not at all) to 3 (almost every day). The total scores range between 0 and 27 and the higher scores indicate a higher severity of depressive symptoms. Previous studies used a score $\geq 5$ to indicate the presence of elevated depressive symptoms [27-29,38,40]; thus, we used this cut-off point to divide participants into a Depressive group (DEP) and non-depressive group (non-DEP). We evaluated anxiety symptoms using the Generalized Anxiety Disorder Questionnaire 7-item scale (GAD-7) [41], with each question rated from 0 (not at all) to 3 (almost every day). The total scores range from 0 to 21 and higher scores indicate a higher severity of anxiety symptoms. In previous studies, a score $\geq 5$ was used to indicate the presence of anxiety symptoms [27-29,40,41]; thus, we used this cut-off point to divide participants into an anxiety group (ANX) and a non-anxiety group (non-ANX). 


\subsection{Demographic, Work-Related, and COVID-19-Related Variables}

The participants also reported their demographic information, including age, gender, marital status, number of children, education, family income, and alcohol consumption. We also collected information on work-related variables: occupation, type of employment, position classification, work pattern, frequency of working at home, service years, and overtime hours per month. Further, we collected demographic and work-related information that was associated with COVID-19: living in COVID-19 special precautions areas (i.e., Hokkaido, Tokyo, Kanagawa, Saitama, Chiba, Aichi, Osaka, Hyogo, Kyoto, Fukuoka, and Okinawa) or not; the incidence of familiar persons infected by COVID-19; the incidence of contact with a COVID-19 patient; physical distance to coworkers: $\geq 1.5 \mathrm{~m}$ or not, physical distance to clients: $\geq 1.5 \mathrm{~m}$ or not; and anxiety level for COVID-19. Anxiety and fear for COVID-19 were measured by asking, "Are you worried about COVID-19?" The responses were scored on a 7-point Likert-type scale (ranging from $1=$ Not at all to $7=$ Feel strongly). The higher the score, the greater the level of COVID-19 anxiety.

\subsection{Statistical Analyses}

Using the cut-off point, we divided the participants into a DEP and non-DEP group and an ANX and non-ANX group, respectively. We defined the inclusion criteria for the DEP and ANX groups as dependent variables, and we defined the demographic variables, workrelated variables, COVID-19-related variables, and the six GJSQ subscales as independent variables. Univariate logistic regression analyses were performed to estimate the adjusted odds ratios (AORs) of the demographic variables, work-related variables, COVID-19related variables, and the six GJSQ subscales for the DEP and ANX groups. According to the tertile scores, the GJSQ subscales were subdivided into low, moderate, and high categories. Subsequently, the AORs for belonging to the DEP and ANX groups were estimated by multivariate logistic regression analyses and adjusted for all the demographic variables, work-related variables, COVID-19-related variables, and the six subdivided GJSQ subscales. Statistical significance was set at $p<0.05$. Statistical data analyses were performed by SPSS version 26.0 software (SPSS Inc., Chicago, IL, USA).

\section{Results}

Table 1 shows the demographic, work-related, and COVID-19-related characteristics of the participants. Six-hundred twenty-one (77\%) participants were male, with a mean age of 46.6 years $(\mathrm{SD}=10.5)$. Regarding the work-related variables, $659(81.7 \%)$ participants were regular workers, 688 (85.3\%) daytime workers, 440 (54.5\%) non-managers, and $578(71.6 \%)$ reported to their workplace daily. The average service years were 13.9 years $(\mathrm{SD}=11.2)$ and the overtime hours per month were $16.2 \mathrm{~h}(\mathrm{SD}=20.5)$. Regarding the COVID-19-related characteristics, $530(65.7 \%)$ participants lived in special precautions areas due to COVID-19, $68(8.4 \%)$ had at least one family member or coworker who was infected with COVID-19, and $58(7.2 \%)$ had contact with at least one COVID-19 patient. Five hundred twenty-six $(65.2 \%)$ participants worked in a setting without a physical distance of more than $1.5 \mathrm{~m}$ among coworkers, and 691 (85.6\%) worked without a physical distance of more than $1.5 \mathrm{~m}$ to clients. Table 2 shows the GJSQ, PHQ-9, and GAD-7 scores of 807 non-HCWs. The PHQ-9 scores were 5.2 (SD = 5.0) and GAD-7 scores were $3.8(\mathrm{SD}=4.5)$. The prevalence of depressive and anxiety symptoms was $43.4 \%$ and $31.8 \%$, respectively. 
Table 1. Participants' socio-demographic characteristics and work environment $(\mathrm{N}=807)$.

\begin{tabular}{|c|c|}
\hline Age (Years) & $\mathrm{n}(\%)$ \\
\hline $20-29$ & $55(6.8)$ \\
\hline $30-39$ & $153(19.0)$ \\
\hline $40-49$ & $259(32.1)$ \\
\hline $50-59$ & $244(30.2)$ \\
\hline$\geq 60$ & $96(11.9)$ \\
\hline \multicolumn{2}{|l|}{ Gender } \\
\hline Male & $621(77)$ \\
\hline Female & $186(23)$ \\
\hline \multicolumn{2}{|l|}{ Marital status } \\
\hline Married & $523(64.8)$ \\
\hline Single & $284(35.2)$ \\
\hline \multicolumn{2}{|l|}{ Child(ren) } \\
\hline None & $346(42.9)$ \\
\hline$\geq 1$ & $461(57.1)$ \\
\hline \multicolumn{2}{|l|}{ Education (years) } \\
\hline$\leq 12$ & $183(22.7)$ \\
\hline$\geq 13$ & $624(77.3)$ \\
\hline \multicolumn{2}{|l|}{ Family income (million yen) } \\
\hline$<4$ & $182(22.6)$ \\
\hline $4-8$ & $374(46.3)$ \\
\hline $8-12$ & $187(23.2)$ \\
\hline$>12$ & $64(7.9)$ \\
\hline \multicolumn{2}{|l|}{ Occupation } \\
\hline Clerical worker & $238(29.5)$ \\
\hline Technical worker & $206(25.5)$ \\
\hline Workers (not clerical and technical) & $204(25.3)$ \\
\hline Civil servants & $56(6.9)$ \\
\hline Executives & $28(3.5)$ \\
\hline Self-employment & $75(9.3)$ \\
\hline \multicolumn{2}{|l|}{ Type of employment } \\
\hline Regular & $659(81.7)$ \\
\hline Temporary & $148(18.3)$ \\
\hline \multicolumn{2}{|l|}{ Position classification } \\
\hline Non-manager & $440(54.5)$ \\
\hline Manager & $367(45.5)$ \\
\hline \multicolumn{2}{|l|}{ Work pattern } \\
\hline Daytime & $688(85.3)$ \\
\hline Shift & $119(14.7)$ \\
\hline \multicolumn{2}{|l|}{ Frequency of working at home } \\
\hline None (every day at workplace) & $578(71.6)$ \\
\hline$\leq$ Twice per week & $103(12.8)$ \\
\hline$>3$ times per week & $126(15.6)$ \\
\hline \multicolumn{2}{|l|}{ Service years } \\
\hline \multicolumn{2}{|l|}{ Overtime (hours/month) } \\
\hline \multicolumn{2}{|l|}{ Alcohol consumption } \\
\hline None & $215(26.7)$ \\
\hline Once per month & $121(15)$ \\
\hline$<1$ per week & $131(16.2)$ \\
\hline 2-3 times per week & $97(12)$ \\
\hline$>4$ times per week & $243(30.1)$ \\
\hline
\end{tabular}


Table 1. Cont.

\begin{tabular}{lc}
\hline $\begin{array}{l}\text { Special precautions area due to COVID-19 } \\
\text { Yes }\end{array}$ & $530(65.7)$ \\
No & $277(34.3)$ \\
\hline Familiar person infected COVID-19 (family, coworker) & $68(8.4)$ \\
$\quad$ Positive & $739(91.6)$ \\
$\quad$ None & \\
\hline Contact with COVID-19 patient & $58(7.2)$ \\
Positive & $749(92.8)$ \\
$\quad$ None & \\
\hline Physical distance to a coworker: $\geq 1.5 \mathrm{~m}$ & $281(34.8)$ \\
Positive & $526(65.2)$ \\
$\quad$ None & \\
\hline Physical distance to a client: $\geq 1.5 \mathrm{~m}$ & $116(14.4)$ \\
Positive & $691(85.6)$ \\
$\quad$ None & \\
\hline
\end{tabular}

Table 2. Participants' occupational stress, depressive, and anxiety symptoms ( $\mathrm{N}=807)$.

\begin{tabular}{lcc}
\hline & Range & Mean (SD) \\
\hline Anxiety for COVID-19 & $1-7$ & $4.6(1.8)$ \\
\hline GJSQ scores & & \\
Quantitative workload & $11-55$ & $34.4(6.4)$ \\
Job control & $16-80$ & $47.8(10.7)$ \\
Job future ambiguity & $4-20$ & $17.4(5.4)$ \\
Variance in workload & $3-15$ & $9.3(2.5)$ \\
Supervisors' support & $4-20$ & $12.7(3.9)$ \\
Coworkers' support & $4-20$ & $13.3(3.7)$ \\
\hline PHQ-9 & $0-27$ & $5.2(5.0)$ \\
\hline GAD-7 & $0-21$ & $3.8(4.5)$ \\
\hline
\end{tabular}

Abbreviations: GJSQ: Generic Job Stress Questionnaire; PHQ: Patient Health Questionnaire; GAD-7: Generalized Anxiety Disorder 7-item Scale; and SD: Standard deviation.

Tables 3 and 4 show the results of the logistic regression analysis. The AORs were calculated using the demographic variables, work-related variables, COVID-19-related variables, and each of the six subdivided GJSQ subscales as independent variables, with the DEP and ANX groups as dependent variables. When entering the independent variables in a multivariate logistic regression analysis, the depressive symptoms were associated with a family income of more than 12 million yen (approximately USD 110 thousand; AOR $=0.45$, $95 \% \mathrm{CI}=0.20-0.99)$; being an executive (AOR $=0.22,95 \% \mathrm{CI}=0.07-0.75)$; having contact with a COVID-19 patient (AOR = 3.14, 95\% CI = 1.60-6.18); "job future ambiguity" for the participants with a moderate $(\mathrm{AOR}=1.83,95 \% \mathrm{CI}=1.17-2.87)$ and high (AOR $=2.17$, $95 \% \mathrm{CI}=1.39-3.39$ ) level of stress; "variance in workload" for participants with a high level of stress $(\mathrm{AOR}=2.20,95 \% \mathrm{CI}=1.36-3.55)$; and "social support from coworkers" for participants with a high level of stress (AOR $=0.36,95 \% \mathrm{CI}=0.21-0.62)$. Anxiety symptoms were associated with having contact with a COVID-19 patient (AOR $=2.85$, $95 \% \mathrm{CI}=1.48-5.49)$; "job future ambiguity" for participants with a moderate (AOR = 1.89, $95 \% \mathrm{CI}=1.17-3.06)$ and high $(\mathrm{AOR}=2.05,95 \% \mathrm{CI}=1.27-3.30)$ level of stress; "variance in workload" for participants with a high level of stress (AOR = 2.05, 95\% CI = 1.25-3.37); and "social support from coworkers" for participants with a high level of stress (AOR $=0.37$, $95 \% \mathrm{CI}=0.21-0.65)$. All the results of the logistic regression analysis are presented in the Tables 3 and 4 . 
Table 3. Multiple logistic regression analysis of risk factors related to the DEP group, compared with the non-DEP group.

\begin{tabular}{|c|c|c|c|c|c|c|}
\hline & \multicolumn{3}{|c|}{ Univariate Model } & \multicolumn{3}{|c|}{ Adjusted Model * } \\
\hline & AOR & $(95 \% \mathrm{CI})$ & $p$ & AOR & $(95 \% \mathrm{CI})$ & $p$ \\
\hline \multicolumn{7}{|l|}{ Family income (million yen) } \\
\hline$<400$ & Ref & & & Ref & & \\
\hline $400-800$ & 0.76 & $(0.53-1.08)$ & 0.121 & 0.87 & $(0.57-1.32)$ & 0.520 \\
\hline $800-1200$ & 0.55 & $(0.36-0.83)$ & $<0.01$ & 0.65 & $(0.38-1.12)$ & 0.119 \\
\hline$>1200$ & 0.31 & $(0.16-0.58)$ & $<0.001$ & 0.45 & $(0.20-0.99)$ & 0.040 \\
\hline \multicolumn{7}{|l|}{ Occupation } \\
\hline Clerical worker & Ref & & & Ref & & \\
\hline Technical worker & 0.98 & $(0.68-1.43)$ & 0.928 & 1.22 & $(0.78-1.93)$ & 0.390 \\
\hline Workers (not clerical and technical) & 1.19 & $(0.82-1.74)$ & 0.354 & 1.33 & $(0.84-2.08)$ & 0.220 \\
\hline Civil servants & 0.70 & $(0.39-1.29)$ & 0.254 & 0.88 & $(0.44-1.79)$ & 0.73 \\
\hline Executives & 0.21 & $(0.07-0.63)$ & $<0.01$ & 0.22 & $(0.07-0.75)$ & 0.015 \\
\hline Self-employment & 0.94 & $(0.56-1.59)$ & 0.825 & 0.70 & $(0.35-1.39)$ & 0.310 \\
\hline \multicolumn{7}{|l|}{ Contact with a COVID-19 patient } \\
\hline None & Ref & & & Ref & & \\
\hline Positive & 2.66 & $(1.52-4.66)$ & $<0.01$ & 3.14 & $(1.60-6.18)$ & $<0.001$ \\
\hline \multicolumn{7}{|l|}{ Occupational stress } \\
\hline \multicolumn{7}{|l|}{ Quantitative workload } \\
\hline Low & Ref & & & Ref & & \\
\hline Moderate & 1.40 & $(0.98-2.00)$ & 0.067 & 1.18 & $(0.75-1.85)$ & 0.470 \\
\hline High & 1.47 & $(1.03-2.09)$ & $<0.05$ & 1.11 & $(0.68-1.83)$ & 0.670 \\
\hline \multicolumn{7}{|l|}{ Job control } \\
\hline High & Ref & & & Ref & & \\
\hline Moderate & 1.54 & $(1.09-2.17)$ & $<0.05$ & 1.14 & $(0.74-1.77)$ & 0.550 \\
\hline Low & 1.50 & $(1.07-2.10)$ & $<0.05$ & 1.31 & $(0.87-1.98)$ & 0.200 \\
\hline \multicolumn{7}{|l|}{ Job future ambiguity } \\
\hline Low & Ref & & & Ref & & \\
\hline Moderate & 2.11 & $(1.44-3.09)$ & $<0.001$ & 1.83 & $(1.17-2.87)$ & $<0.01$ \\
\hline High & 2.86 & $(1.96-4.17)$ & $<0.001$ & 2.17 & $(1.39-3.39)$ & $<0.001$ \\
\hline \multicolumn{7}{|l|}{ Variance in workload } \\
\hline Low & Ref & & & Ref & & \\
\hline Moderate & 1.18 & $(0.81-1.71)$ & 0.401 & 1.26 & $(0.79-2.02)$ & 0.340 \\
\hline High & 1.79 & $(1.28-2.52)$ & $<0.01$ & 2.20 & $(1.36-3.55)$ & $<0.001$ \\
\hline \multicolumn{7}{|l|}{ Social support from supervisor } \\
\hline Low & Ref & & & Ref & & \\
\hline Moderate & 0.49 & $(0.35-0.69)$ & $<0.001$ & 0.67 & $(0.44-1.04)$ & 0.080 \\
\hline High & 0.30 & $(0.21-0.43)$ & $<0.001$ & 0.64 & $(0.38-1.07)$ & 0.090 \\
\hline \multicolumn{7}{|l|}{ Social support from coworker } \\
\hline Low & Ref & & & Ref & & \\
\hline Moderate & 0.51 & $(0.36-0.74)$ & $<0.001$ & 0.65 & $(0.41-1.02)$ & 0.060 \\
\hline High & 0.26 & $(0.18-0.38)$ & $<0.001$ & 0.36 & $(0.21-0.62)$ & $<0.001$ \\
\hline
\end{tabular}

*: Adjusted for all the listed variables. Abbreviations: $\mathrm{CI}=$ Confidence interval; $\mathrm{AOR}=$ Adjusted odds ratio; and DEP $=$ Depressive. 
Table 4. Multiple logistic regression analysis of the risk factors related to the ANX group, compared with the non-ANX group.

\begin{tabular}{|c|c|c|c|c|c|c|}
\hline & \multicolumn{3}{|c|}{ Univariate Model } & \multicolumn{3}{|c|}{ Adjusted Model * } \\
\hline & AOR & $(95 \% \mathrm{CI})$ & $p$ & AOR & $(95 \% \mathrm{CI})$ & $p$ \\
\hline \multicolumn{7}{|c|}{ Contact with COVID-19 patient } \\
\hline None & Ref & & & Ref & & \\
\hline Positive & 2.46 & $(1.44-4.22)$ & $<0.001$ & 2.85 & $(1.48-5.49)$ & $<0.01$ \\
\hline \multicolumn{7}{|c|}{ Occupational stress } \\
\hline \multicolumn{7}{|c|}{ Quantitative workload } \\
\hline Low & Ref & & & Ref & & \\
\hline Moderate & 1.29 & $(0.88-1.90)$ & 0.192 & 1.12 & $0.69-1.79$ & 0.650 \\
\hline High & 1.41 & $(0.97-2.06)$ & 0.074 & 1.04 & $0.62-1.73$ & 0.900 \\
\hline \multicolumn{7}{|l|}{ Job control } \\
\hline High & Ref & & & Ref & & \\
\hline Moderate & 1.30 & $(0.91-1.87)$ & 0.155 & 1.11 & $0.70-1.74$ & 0.660 \\
\hline Low & 1.01 & $(0.71-1.45)$ & 0.940 & 0.83 & $0.54-1.29$ & 0.410 \\
\hline \multicolumn{7}{|c|}{ Job future ambiguity } \\
\hline Low & Ref & & & Ref & & \\
\hline Moderate & 1.96 & $(1.29-2.97)$ & $<0.01$ & 1.89 & $1.17-3.06$ & $<0.01$ \\
\hline High & 2.49 & $(1.65-3.75)$ & $<0.001$ & 2.05 & $1.27-3.30$ & $<0.01$ \\
\hline \multicolumn{7}{|c|}{ Variance in workload } \\
\hline Low & Ref & & & Ref & & \\
\hline Moderate & 1.15 & $(0.77-1.74)$ & 0.494 & 1.30 & $0.78-2.16$ & 0.310 \\
\hline High & 1.76 & $(1.22-2.53)$ & $<0.01$ & 2.05 & $1.25-3.37$ & $<0.01$ \\
\hline \multicolumn{7}{|c|}{ Social support from supervisor } \\
\hline Low & Ref & & & Ref & & \\
\hline Moderate & 0.54 & $(0.38-0.76)$ & $<0.01$ & 0.68 & $0.44-1.05$ & 0.080 \\
\hline High & 0.32 & $(0.22-0.47)$ & $<0.001$ & 0.70 & $0.40-1.20$ & 0.190 \\
\hline \multicolumn{7}{|c|}{ Social support from coworker } \\
\hline Low & Ref & & & Ref & & \\
\hline Moderate & 0.57 & $(0.39-0.82)$ & $<0.01$ & 0.78 & $0.49-1.22$ & 0.280 \\
\hline High & 0.26 & $(0.18-0.39)$ & $<0.001$ & 0.37 & $0.21-0.65$ & $<0.001$ \\
\hline
\end{tabular}

*: Adjusted for all the listed variables. Abbreviations: $\mathrm{CI}=$ Confidence interval; AOR = Adjusted odds ratio; and ANX = Anxiety.

\section{Discussion}

The results indicate a relationship between the variance in workload, job future ambiguity, social support from coworkers, having contact with a COVID-19 patient, and depressive and anxiety symptoms, and a relationship between socioeconomic status and depressive symptoms. However, there were no relationships between the quantitative workload, job control, depressive, and anxiety symptoms. To our knowledge, this is the first study to identify the relationships between occupational stress and change in the work environment due to COVID-19 and depressive and anxiety symptoms among non-HCWs during the COVID-19 pandemic.

Kuzman et al. proposed eight basic principles for the organization of mental health care. They emphasized that there should be no substantial differences in the provision of health care for COVID-19 between persons with pre-existing mental health disorders and those without previous disorders [42]. McDaid D stated that the economic recovery in Europe depends on the physical and mental health of its citizens; the support for mental health recovery needs to be accurately portrayed as a positive investment that will benefit society rather than a cost to be minimized [43]. Non-HCWs are both persons with and those without pre-existing mental health disorders. Therefore, careful attention should be paid to them for the benefit of society. 
The prevalence of depressive and anxiety symptoms was $43.4 \%$ and $31.8 \%$, respectively, in this study. Previous studies conducted with the general population during the COVID19 pandemic, using cut-off scores $\geq 5$ on the PHQ-9 and the GAD-7, reported that the prevalence of depressive symptoms (i.e., PHQ-9) was 52.5\% in the United States [44] and $27.9 \%$ [27] and 43.7\% [29] in China, and the prevalence of anxiety symptoms (i.e., GAD-7) was 31.6\% [27] and 37.4\% [29] in China. This study was conducted during the third wave of the COVID-19 pandemic in Japan when the number of new COVID-19 cases, new COVID-19 serious cases, and hospitalized COVID-19 patients increased more rapidly than in the first and second waves, and Japan's second state of emergency was enforced. These conditions were the reasons for the relatively high prevalence of depressive and anxiety symptoms among non-HCWs in this study.

This study identified the relationship between having contact with a COVID-19 patient and depressive and anxiety symptoms. Being infected by either confirmed or suspected COVID-19, having any family members or friends infected by COVID-19, and having occupational exposure risks to patients infected with COVID-19 were found to be risk factors for elevated depressive and anxiety symptoms among the general population in China [27]. Another study of 123,768 factory workers during the pandemic in China, reported that having COVID-19 confirmed cases in the community and having COVID19 confirmed friends were associated with an increased risk of depressive and anxiety symptoms [19]. Similarly, an increased risk of depressive symptoms during the COVID-19 pandemic was associated with greater exposure to stress (e.g., losing a job, the death of someone close owing to COVID-19, and having financial problems) in the United States [44]. The Centers for Disease Control and Prevention (CDC) indicated that the "Concern about the risk of being exposed to the virus at work" was a potential common work-related factor [45]. The results of this study were consistent with previous studies. Reducing contact with COVID-19 patients in the workplace appears to be a factor that may protect against depressive and anxiety symptoms among non-HCWs.

The relationships between job future ambiguity, the variance in workload, support from coworkers, and depressive and anxiety symptoms during the COVID-19 pandemic were also demonstrated in this study. However, there were no relationships between the quantitative workload, job control, and social support from supervisors and depressive and anxiety symptoms. Before the COVID-19 pandemic, many longitudinal studies and meta-analyses had demonstrated that a higher quantitative workload, lower job control, lower social support, and a higher job strain were associated with the risk of depressive symptoms [20-23]. These occupational stress were primarily viewed as risk factors for mental health problems in the workplace. Job future ambiguity refers to any uncertainty regarding a promotion, skill development, or increase in responsibilities that an individual can experience at work. As for job future ambiguity, before the COVID-19 pandemic, the relationships between depressive symptoms and job future ambiguity were reported among HCWs in public hospitals in Qatar [46], and we demonstrated that anxious temperament predicted a higher level of job future ambiguity among Japanese civil servants [47]. The variance in workload refers to the extent of a marked increase in workload, the amount of concentration required on work tasks, and the speed required to complete work tasks. As for the variance in workload, before the COVID-19 pandemic, previous research indicated that variance in workload was associated with depressive symptoms among Japanese firefighters [37] and heavy drinking among female Japanese teachers [36]. However, little research on job future ambiguity and variance in the workload as occupational stress has been conducted. No studies have focused on the relationship between variance in workload and depressive and anxiety symptoms, and a few studies have focused on the relationship between job future ambiguity and depressive and anxiety symptoms during the COVID-19 pandemic. A study in Serbia among different categories of employees, demonstrated that job uncertainty and the fear of COVID-19 related to work-related distress [48]. In the U.S.A., another study among white-collar employees indicated that job insecurity has a substantial impact on depressive and anxiety symptoms, [49]. Moreover, few studies 
have mentioned non-HCWs' occupational stress during the COVID-19 pandemic, although the CDC has indicated potential common work-related factors that can increase stress during the COVID-19 pandemic; these include the "Uncertainty about the future of your workplace and/or employment," "Managing a different workload," "Lack of access to the tools and equipment needed to perform your job," "Learning new communication tools and dealing with technical difficulties," and "Adapting to a different workspace and/or work schedule" [45]. These factors identified by the CDC support the results of this study.

The COVID-19 pandemic lasted globally for more than one year. It has led to drastic workstyle changes in the workplace, economic deterioration, dismissal, and feelings of job insecurity or ambiguity, leading to an increase in "job future ambiguity." Further, the unexpected and sudden change in the work environment, such as coworkers' absence due to a SARS-CoV-2 infection, having close contact with a COVID-19 patient (e.g., self, coworker, and family), and a change of work policy and workstyle (e.g., telework and remote working) lead to an increase in "variance in workload." These two occupational stresses are expected to have a large influence on the mild depressive symptoms and anxiety of non-HCWs. Conversely, the support from coworkers appears to serve a protective role against depressive and anxiety symptoms of non-HCWs, although maintaining frequent inperson social contact has been difficult during the pandemic. Sufficient communication with coworkers was a source of social support [50] to reduce emotional exhaustion [51] before the pandemic. A longitudinal study during the pandemic among software professionals living in the U.S.A. and Europe indicated that promoting effective communication among coworkers can help to maintain a better mental health status [52]. Therefore, promoting indirect contact with coworkers using online communication tools and supporting each other will be essential during the COVID-19 pandemic.

The effect of variance in workload, job future ambiguity, and contact with COVID-19 patients on depressive and anxiety symptoms might be greater for non-HCWs during the COVID-19 pandemic rather than before the pandemic, and the effect of occupational stress on depressive and anxiety symptoms during the COVID-19 pandemic might differ from that before the pandemic.

For companies and workplaces, some countermeasures for employees' occupational stress are needed during the COVID-19 pandemic. First, clarifying the job and company's prospects, even if the prospects are good or bad, are likely to reduce "job future ambiguity." Non-HCWs strongly fear being out of business and becoming downsized; therefore, employment stability is likely the greatest protective factor against anxiety and depressive symptoms. Second, securing adequate human resources and reducing the workload is critical for reducing the occupational stress related to "variance in workload." Third, creating a work environment that supports communication among coworkers and strengthens social support among coworkers is important. Enhanced social support by focusing on changes in workers' performance (reduced work efficiency) and interactions (the deterioration of relationships with colleagues and superiors) in the workplace are necessary for the early detection of major depressive disorder [53]. Fourth, taking all available COVID-19 precautions, such as assessing job hazards for the feasibility of engineering controls, ensuring ventilation and water systems operate properly, altering workspaces to maintain physical distancing, temperature and symptom screening, encouraging sick workers to report symptoms, encouraging physical distancing and wearing masks in the workplace, and using technology to promote physical distancing [54], are essential for protecting employees from SARS-CoV-2 infection.

Non-HCWs should become better at recognizing their symptoms of stress (e.g., feeling irritable, angry, nervous, anxious, tired, overwhelmed, burned out, depressed, or experiencing sleeplessness) [45], consulting reliable persons (e.g., family, friends, coworkers, supervisors, or counselors), and having various coping skills for depressive and anxiety symptoms. For example, cognitive-behavioral therapy [55,56] and mindfulness [57] are effective for employees' prevention of depressive and anxiety symptoms. Similarly, Morita 
therapy, an indigenous Japanese therapy from Masatake Morita [58-60], has been proven as effective in reducing depressive and anxiety symptoms.

There are several limitations to the present study. First, it may be difficult to generalize our findings to different countries and cultures as only Japanese non-HCWs were surveyed and the infection status, infection control measures, and type of lockdown implemented to control the COVID-19 pandemic differ among countries. Further, the number of participants was small, the data were obtained from web-based sources, and the representativeness of the study sample is unknown. Second, occupational stress and depressive and anxiety symptoms were assessed using self-report; thus, the response bias may have influenced the results, and some misclassification might exist. Third, a cross-sectional design was used; therefore, our findings cannot examine the causal relationship between occupational stress and depressive and anxiety symptoms, nor can the directionality of any such relationship be established. A cohort or longitudinal design is necessary to examine this causal relationship in-depth among non-HCWs and would be beneficial in the future. Fourth, we have no data on the same workers without the effect of COVID-19, and the number of HCWs in this study was too small. Therefore, there is no other group of workers for comparison. Fifth, there is uneven gender distribution as the study sample comprised of $77 \%$ males. Sixth, anxiety and fear for COVID-19 were measured in this study by asking one question, "Are you worried about COVID-19?". This is an original tool created by us and its reliability and validity have not been assessed.

\section{Conclusions}

We identified two significant relationships in this study: a relationship between variance in workload, job future ambiguity, social support from coworkers, contact with COVID-19 patients, and depressive and anxiety symptoms, and a relationship between the socioeconomic status and depressive symptoms among Japanese non-HCWs during the COVID-19 pandemic. In addition, the effect of occupational stress on depressive and anxiety symptoms during the COVID-19 pandemic differed from the effects reported before the pandemic.

Paying attention to job future ambiguity, variance in workload at the workplace and individual perspectives, promoting contact among coworkers using online communication tools, and reducing contact with COVID-19 patients are likely to be useful in decreasing the depressive and anxiety symptoms of non-HCWs.

Author Contributions: Conceptualization, Y.D. and S.I.; methodology, Y.D. and S.I.; software, Y.D.; validation, Y.D.; formal analysis, Y.D.; investigation, Y.D.; resources, Y.D.; data curation, Y.D. and S.I.; writing—original draft preparation, Y.D.; writing—review and editing, S.I., A.N., A.K., T.H., Y.S., Y.N., Y.O., Y.U., and K.I.; supervision, S.I.; project administration, K.I. All authors have read and agreed to the published version of the manuscript.

Funding: This research received no external funding.

Institutional Review Board Statement: This study was conducted in accordance with the Declaration of Helsinki, and the study design was approved by the Human Subjects Review Committee at Osaka City University (Authorization Number 1409) prior to the study.

Informed Consent Statement: Participants were informed that their participation was voluntary. All participants provided their full informed consent at the top of their questionnaire, and were assured that the researchers were not given access to any of their private, identifying information (e.g., name, phone number, and home address) from Macromill, Inc. All data were stored only in our database, and the participants' employers or the institutions did not have access to the data or know who had participated in the study.

Data Availability Statement: All the data generated or analyzed during this study are included in this published article.

Acknowledgments: We give sincere thanks to all the participants in this study.

Conflicts of Interest: The authors declare no conflict of interest. 


\section{References}

1. World Health Organization. COVID-19 Weekly Epidemiological Update; WHO: Geneva, Switzerland, 2021.

2. Fiorillo, A.; Gorwood, P. The consequences of the COVID-19 pandemic on mental health and implications for clinical practice. Eur. Psychiatry 2020, 63, e32. [CrossRef]

3. Daly, M.; Sutin, A.; Robinson, E. Longitudinal changes in mental health and the COVID-19 pandemic: Evidence from the UK Household Longitudinal Study. Psychol. Med. 2020, 1-10. [CrossRef] [PubMed]

4. Xiong, J.; Lipsitz, O.; Nasri, F.; Lui, L.M.W.; Gill, H.; Phan, L.; Chen-Li, D.; Iacobucci, M.; Ho, R.; Majeed, A.; et al. Impact of COVID-19 pandemic on mental health in the general population: A systematic review. J. Affect. Disord. 2020, 277, 55-64. [CrossRef] [PubMed]

5. Luo, M.; Guo, L.; Yu, M.; Jiang, W.; Wang, H. The psychological and mental impact of coronavirus disease 2019 (COVID-19) on medical staff and general public: A systematic review and meta-analysis. Psychiatry Res. 2020, 291, 113190. [CrossRef]

6. Wang, Y.; Kala, M.P.; Jafar, T.H. Factors associated with psychological distress during the coronavirus disease 2019 (COVID-19) pandemic on the predominantly general population: A systematic review and meta-analysis. PLoS ONE 2020, 15, e0244630. [CrossRef] [PubMed]

7. Li, Y.; Scherer, N.; Felix, L.; Kuper, H. Prevalence of depression, anxiety and post-traumatic stress disorder in health care workers during the COVID-19 pandemic: A systematic review and meta-analysis. PLoS ONE 2021, 16, e0246454. [CrossRef]

8. Yuan, K.; Gong, Y.-M.; Liu, L.; Sun, Y.-K.; Tian, S.-S.; Wang, Y.-J.; Zhong, Y.; Zhang, A.-Y.; Su, S.-Z.; Liu, X.-X.; et al. Prevalence of posttraumatic stress disorder after infectious disease pandemics in the twenty-first century, including COVID-19: A meta-analysis and systematic review. Mol. Psychiatry 2021, 26, 4982-4998. [CrossRef]

9. Busch, I.M.; Moretti, F.; Mazzi, M.; Wu, A.W.; Rimondini, M. What we have learned from two decades of epidemics and pandemics: A systematic review and meta-analysis of the psychological burden of frontline healthcare workers. Psychother. Psychosom. 2021, 90, 178-190. [CrossRef]

10. Santabárbara, J.; Bueno-Notivol, J.; Lipnicki, D.M.; Olaya, B.; Pérez-Moreno, M.; Gracia-García, P.; Idoiaga-Mondragon, N.; Ozamiz-Etxebarria, N. Prevalence of anxiety in health care professionals during the COVID-19 pandemic: A rapid systematic review (on published articles in Medline) with meta-analysis. Prog. Neuropsychopharmacol. Biol. Psychiatry 2021, 107, 110244. [CrossRef]

11. De Kock, J.H.; Latham, H.A.; Leslie, S.J.; Grindle, M.; Munoz, S.; Ellis, L.; Polson, R.; Malley, C.M.O. A rapid review of the impact of COVID-19 on the mental health of healthcare workers: Implications for supporting psychological well-being. BMC Public Health 2021, 21, 104. [CrossRef]

12. Wu, T.; Jia, X.; Shi, H.; Niu, J.; Yin, X.; Xie, J.; Wang, X. Prevalence of mental health problems during the COVID-19 pandemic: A systematic review and meta-analysis. J. Affect. Disord. 2021, 281, 91-98. [CrossRef]

13. Serrano-ripoll, M.J.; Meneses-echavez, J.F.; Ricci-cabello, I. Impact of viral epidemic outbreaks on mental health of healthcare workers: A rapid systematic review and meta-analysis. J. Affect. Disord. 2020, 277, 347-357. [CrossRef]

14. da Silva, F.C.T.; Neto, M.L.R. Psychiatric symptomatology associated with depression, anxiety, distress, and insomnia in health professionals working in patients affected by COVID-19: A systematic review with meta-analysis. Prog. Neuropsychopharmacol. Biol. Psychiatry 2021, 104, 110057. [CrossRef] [PubMed]

15. Salazar, G.; Pablo, D.; Vaquerizo-serrano, J.; Catalan, A.; Arango, C.; Moreno, C.; Ferre, F.; Il, J.; Sullivan, S.; Brondino, N. Impact of coronavirus syndromes on physical and mental health of health care workers: Systematic review and meta-analysis. J. Affect. Disord. 2020, 275, 48-57. [CrossRef] [PubMed]

16. Huang, Y.; Zhao, N. Generalized anxiety disorder, depressive symptoms and sleep quality during COVID-19 outbreak in China: A web-based cross-sectional survey. Psychiatry Res. 2020, 288, 112954. [CrossRef] [PubMed]

17. Zhang, W.R.; Wang, K.; Yin, L.; Zhao, W.F.; Xue, Q.; Peng, M.; Min, B.Q.; Tian, Q.; Leng, H.X.; Du, J.L.; et al. Mental health and psychosocial problems of medical health workers during the COVID-19 epidemic in China. Psychother. Psychosom. 2020, 89, 242-250. [CrossRef] [PubMed]

18. Sasaki, N.; Kuroda, R.; Tsuno, K.; Kawakami, N. The deterioration of mental health among healthcare workers during the covid-19 outbreak: A population-based cohort study of workers in Japan. Scand. J. Work Environ. Health 2020, 46, 639-644. [CrossRef]

19. Zhang, X.R.; Huang, Q.M.; Wang, X.M.; Cheng, X.; Li, Z.H.; Wang, Z.H.; Zhong, W.F.; Liu, D.; Shen, D.; Chen, P.L.; et al. Prevalence of anxiety and depression symptoms, and association with epidemic-related factors during the epidemic period of COVID-19 among 123,768 workers in China: A large cross-sectional study. J. Affect. Disord. 2020, 277, 495-502. [CrossRef]

20. Tatsuse, T.; Sekine, M.; Yamada, M. The contributions made by job satisfaction and psychosocial stress to the development and persistence of depressive symptoms: A 1-year prospective study. J. Occup. Environ. Med. 2019, 61, 190-196. [CrossRef]

21. Åhlin, J.K.; Lamontagne, A.D.; Magnusson Hanson, L.L. Are there bidirectional relationships between psychosocial work characteristics and depressive symptoms? A fixed effects analysis of Swedish national panel survey data. Occup. Environ. Med. 2019, 76, 455-461. [CrossRef]

22. Kim, S.Y.; Shin, Y.C.; Oh, K.S.; Shin, D.W.; Lim, W.J.; Cho, S.J.; Jeon, S.W. Gender and age differences in the association between work stress and incident depressive symptoms among Korean employees: A cohort study. Int. Arch. Occup. Environ. Health 2020, 93, 457-467. [CrossRef] [PubMed] 
23. Theorell, T.; Hammarström, A.; Aronsson, G.; Träskman Bendz, L.; Grape, T.; Hogstedt, C.; Marteinsdottir, I.; Skoog, I.; Hall, C. A systematic review including meta-analysis of work environment and depressive symptoms. BMC Public Health 2015, 15, 738. [CrossRef] [PubMed]

24. Duchaine, C.S.; Aubé, K.; Gilbert-Ouimet, M.; Vézina, M.; Ndjaboué, R.; Massamba, V.; Talbot, D.; Lavigne-Robichaud, M.; Trudel, X.; Pena-Gralle, A.P.B.; et al. Psychosocial stressors at work and the risk of sickness absence due to a diagnosed mental disorder: A systematic review and meta-analysis. JAMA Psychiatry 2020, 77, 842-851. [CrossRef] [PubMed]

25. Kristoffersen, E.S.; Winsvold, B.S.; Sandset, E.C.; Storstein, A.M.; Faiz, K.W. Experiences, distress and burden among neurologists in Norway during the COVID-19 pandemic. PLoS ONE 2021, 16, e0246567. [CrossRef]

26. Zhan, Y.; Ma, S.; Jian, X.; Cao, Y.; Zhan, X. The current situation and influencing factors of job stress among frontline nurses assisting in Wuhan in fighting COVID-19. Front. Public Health 2020, 8, 579866. [CrossRef]

27. Shi, L.; Lu, Z.-A.; Que, J.-Y.; Huang, X.-L.; Liu, L.; Ran, M.-S.; Gong, Y.-M.; Yuan, K.; Yan, W.; Sun, Y.-K.; et al. Prevalence of and risk factors associated with mental health symptoms among the general population in China during the Coronavirus disease 2019 pandemic. JAMA Netw. Open 2020, 3, e2014053. [CrossRef]

28. Fu, W.; Wang, C.; Zou, L.; Guo, Y.; Lu, Z.; Yan, S.; Mao, J. Psychological health, sleep quality, and coping styles to stress facing the COVID-19 in Wuhan, China. Transl. Psychiatry 2020, 10, 225. [CrossRef]

29. Zhou, S.J.; Zhang, L.G.; Wang, L.L.; Guo, Z.C.; Wang, J.Q.; Chen, J.C.; Liu, M.; Chen, X.; Chen, J.X. Prevalence and sociodemographic correlates of psychological health problems in Chinese adolescents during the outbreak of COVID-19. Eur. Child Adolesc. Psychiatry 2020, 29, 749-758. [CrossRef]

30. Hurrell, J.J., Jr.; McLaney, M.A. Exposure to job stress-a new psychometric instrument. Scand. J. Work Environ. Health 1988, 14 (Suppl. S1), 27-28.

31. Haratani, T.; Kawakami, N.; Araki, S.; Hurrell, J.J.; Sauter, S.L.; Swanson, N.G. Psychometric properties and stability of the Japanese version of the NIOSH job stress questionnaire. In Proceedings of the 25th International Congress on Occupational Health, Stockholm, Sweden, 15-20 September 1996; p. 393.

32. Haratani, T.; Kawakami, N.; Araki, S. Reliability and validity of the Japanese version of NIOSH Generic Job Questionnaire. Sangyo Igaku. 1993, 35, S214. (In Japanese)

33. Nakada, A.; Iwasaki, S.; Kanchika, M.; Nakao, T.; Deguchi, Y.; Konishi, A.; Ishimoto, H.; Inoue, K. Relationship between depressive symptoms and perceived individual level occupational stress among Japanese schoolteachers. Ind. Health 2016, 54, 396-402. [CrossRef] [PubMed]

34. Nitta, T.; Deguchi, Y.; Iwasaki, S.; Kanchika, M.; Inoue, K. Depression and occupational stress in Japanese school principals and vice-principals. Occup. Med. 2019, 69, 39-46. [CrossRef] [PubMed]

35. Deguchi, Y.; Inoue, K.; Muramatsu, T.; Iwasaki, S.; Yamauchi, T.; Nakao, T.; Muroya, M.; Kobayashi, Y.; Kato, Y.; Kiriike, N. Relationships between occupational stress and depressive symptoms among prison officers in Japan. Osaka City Med. J. 2013, 59, 91-98. [PubMed]

36. Deguchi, Y.; Iwasaki, S.; Kanchika, M.; Nitta, T.; Mitake, T.; Nogi, Y.; Kadowaki, A.; Niki, A.; Inoue, K. Gender differences in the relationships between perceived individual-level occupational stress and hazardous alcohol consumption among Japanese teachers: A cross-sectional study. PLoS ONE 2018, 13, e0204248. [CrossRef] [PubMed]

37. Saijo, Y.; Ueno, T.; Hashimoto, Y. Job stress and depressive symptoms among Japanese fire fighters. Am. J. Ind. Med. 2007, 50, 470-480. [CrossRef]

38. Kroenke, K.; Spitzer, R.L.; Williams, J.B.W. The PHQ-9: Validity of a brief depression severity measure. J. Gen. Intern. Med. 2001, 16, 606-613. [CrossRef]

39. Muramatsu, K.; Miyaoka, H.; Kamijima, K.; Muramatsu, Y.; Tanaka, Y.; Hosaka, M.; Miwa, Y.; Fuse, K.; Yoshimine, F.; Mashima, I.; et al. Performance of the Japanese version of the Patient Health Questionnaire-9 (J-PHQ-9) for depression in primary care. Gen. Hosp. Psychiatry 2018, 52, 64-69. [CrossRef]

40. Li, Z.; Hao, Y.; Han, Y.; Wu, S.; Zhu, D.; Liu, M.; Dong, Q.; Wang, X.; Guan, Y. Prevalence and associated physical symptoms of depressive and anxiety symptoms in neurology outpatient clinic. J. Neurol. Neurosurg. Psychiatry 2019, 90, 1286-1287. [CrossRef]

41. Spitzer, R.L.; Kroenke, K.; Williams, J.B.W.; Löwe, B. A brief measure for assessing generalized anxiety disorder: The GAD-7. Arch. Intern. Med. 2006, 166, 1092-1097. [CrossRef]

42. Kuzman, M.R.; Curkovic, M.; Wasserman, D. Principles of mental health care during the COVID-19 pandemic. Eur. Psychiatry 2020, 63, 6-8. [CrossRef]

43. McDaid, D. Viewpoint: Investing in strategies to support mental health recovery from the COVID-19 pandemic. Eur. Psychiatry 2021, 64, e32. [CrossRef] [PubMed]

44. Ettman, C.K.; Abdalla, S.M.; Cohen, G.H.; Sampson, L.; Vivier, P.M.; Galea, S. Prevalence of depression symptoms in US adults before and during the COVID-19 pandemic. JAMA Netw. Open 2020, 3, e2019686. [CrossRef] [PubMed]

45. Centers for Disease Control and Prevention. Employees: How to Cope with Job Stress and Build Resilience during the COVID-19 Pandemic. Available online: https:/ / www.cdc.gov/coronavirus/2019-ncov/community/mental-health-non-healthcare.html (accessed on 3 May 2021).

46. Yehya, A.; Sankaranarayanan, A.; Alkhal, A.; Alnoimi, H.; Almeer, N.; Khan, A.; Ghuloum, S. Job satisfaction and stress among healthcare workers in public hospitals in Qatar. Arch. Environ. Occup. Health 2020, 75, 10-17. [CrossRef] [PubMed] 
47. Deguchi, Y.; Iwasaki, S.; Konishi, A.; Ishimoto, H.; Ogawa, K.; Fukuda, Y.; Nitta, T.; Inoue, K. the usefulness of assessing and identifying workers' temperaments and their effects on occupational stress in the workplace. PLoS ONE 2016, 11, e0156339. [CrossRef]

48. Blanuša, J.; Barzut, V.; Knežević, J. Intolerance of uncertainty and fear of COVID-19 moderating role in relationship between job insecurity and work-related distress in the Republic of Serbia. Front. Psychol. 2021, 12, 647972. [CrossRef] [PubMed]

49. Obrenovic, B.; Du, J.; Godinic, D.; Baslom, M.M.M.; Tsoy, D. The threat of COVID-19 and job insecurity impact on depression and anxiety: An empirical study in the USA. Front. Psychol. 2021, 12, 648572. [CrossRef]

50. Olsen, H.M.; Brown, W.J.; Kolbe-Alexander, T.; Burton, N.W. Flexible work: The impact of a new policy on employees' sedentary behavior and physical activity. J. Occup. Environ. Med. 2018, 60, 23-28. [CrossRef]

51. Vander Elst, T.; Verhoogen, R.; Sercu, M.; Van Den Broeck, A.; Baillien, E.; Godderis, L. Not extent of telecommuting, but job characteristics as proximal predictors of work-related well-being. J. Occup. Environ. Med. 2017, 59, e180-e186. [CrossRef]

52. Russo, D.; Hanel, P.H.P.; Altnickel, S.; van Berkel, N. Predictors of well-being and productivity among software professionals during the COVID-19 pandemic-A longitudinal study. Empir. Softw. Eng. 2021, 26, 62. [CrossRef]

53. Niki, A.; Deguchi, Y.; Iwasaki, S.; Mitake, T.; Okuda, Y.; Sakaguchi, A.; Hirota, T.; Shirahama, Y.; Nakamichi, Y.; Inoue, K. Gender differences in self-perceived changes among Japanese workers with depression. Occup. Med. 2020, 70, 680-684. [CrossRef]

54. Centers for Disease Control and Prevention. Guidance for Businesses and Employers Responding to Coronavirus Disease 2019 (COVID-19). Available online: https:/ /www.cdc.gov/coronavirus/2019-ncov/community/guidance-business-response.html (accessed on 3 May 2021).

55. Joyce, S.; Modini, M.; Christensen, H.; Mykletun, A.; Bryant, R.; Mitchell, P.B.; Harvey, S.B. Workplace interventions for common mental disorders: A systematic meta-review. Psychol. Med. 2016, 46, 683-697. [CrossRef] [PubMed]

56. Brenninkmeijer, V.; Lagerveld, S.E.; Blonk, R.W.B.; Schaufeli, W.B.; Wijngaards-de Meij, L.D.N.V. Predicting the effectiveness of work-focused CBT for common mental disorders: The influence of baseline self-efficacy, depression and anxiety. J. Occup. Rehabil. 2019, 29, 31-41. [CrossRef] [PubMed]

57. Sun, Y.; Liu, F.; Wang, Y.; Zhou, M.; Yang, B.; Cao, F. Mindfulness improves health worker's occupational burnout: The moderating effects of anxiety and depression. Int. Arch. Occup. Environ. Health 2021, 94, 1297-1305. [CrossRef] [PubMed]

58. Sugg, H.V.R.; Richards, D.A.; Frost, J. Morita Therapy for depression (Morita Trial): A pilot randomised controlled trial. BMJ Open 2018, 8, e021605. [CrossRef] [PubMed]

59. Jia, Y.; Li, M.; Cheng, Z.; Cui, L.; Zhao, J.; Liu, Y.; Leng, M.; Li, F.; Chen, L. Morita therapy for depression in adults: A systematic review and meta-analysis. Psychiatry Res. 2018, 269, 763-771. [CrossRef]

60. Wu, H.; Yu, D.; He, Y.; Wang, J.; Xiao, Z.; Li, C. Morita therapy for anxiety disorders in adults. Cochrane Database Syst. Rev. 2015, 2, CD008619. [CrossRef] 